\title{
Building the city as a stage, the example of Nantes
}

\author{
Emmanuelle Gangloff ${ }^{1, *}$ \\ ${ }^{1}$ Laboratoire Ambiances AAU - CRENAU, ENSA Nantes, 6 Quai François Mitterrand, BP 16202, \\ 44262 Nantes CEDEX 2 Nantes, France
}

\begin{abstract}
At a time when cities try to stand out from one another, the construction of ambiances is brought back to the foreground of urban, social and cultural dynamics in metropolises. With this contribution, we aim at taking the example of Nantes and the Machines of the Isle of Nantes to show the transformations of an industrial territory into a cultural open stage with cultural practices. Indeed, following the shutdown of the shipyards in the 1990 s, the city pursued a major cultural policy to make the industrial wastelands attractive. In successive steps, the temporary artistic practices changed urban ones, based on the question of ambiances and their narrative. Favouring the implementation of projects taking place in public spaces, the city became a $360^{\circ}$-urban scene. As opposed to a generic city, Nantes turned urban scenography into a way to single itself out, by accompanying the creation of plots and narratives around its territory. Between artistic experiments and narrative, Nantes thus appears as a stage-city that invites to include user experiences.
\end{abstract}

\section{Revelation of the dramatic potential by the artists}

With the birth of urbanism, the rise of metropolitan centres as economic actors without intermediaries, and the progressive structuring of street arts as a sector, functionalities coming from a dramatic culture are empowered, which re-activates an archaeological connection between theatre and the city. Indeed, theatre took place outdoors for more than fifteen centuries before being brought indoors in dedicated locations. Throughout the ages, scenographic functionalities were present to organise the connection between representation space and the city [1]. Supported by the emergence of the event, cultural or creative city, the scenographic dimension of artistic projects serves the spectacularisation of cities, the dramatization of public spaces, turning precarious spaces into artistic experiment locations. It allows to reinvent the relations between inhabitants and their city by building an urban imagination. In France, this shift intensified after the events of May 1968. Society needed publication places, and public spaces appeared as potential crossroads. From the 1970s, the artists turned public spaces into means of expression, and the city became a background for theatre. The twentieth century has undergone a remarkable growth in the theatre offer out of its walls, which was available in many forms, either the circus, the fun fair or urban forms. It

\footnotetext{
* Corresponding author: emmanuelle.gangloff@crenau.archi.fr
} 
reconnected with the archaeological aspects of scenography. Stages multiplied, and the city as a whole became a $360^{\circ}$ stage. The cultural democratisation and the desire to establish a new relation to the public encouraged open-air temporary artistic experiments. Simultaneously, outdoors, urban centres developed themselves and convened theatricalness to spaces to strengthen their attractivity. Scenography thus accompanies this evolution of the interface, between play, interactions and processes to make visible. Therefore, the concept of urban scenography can be considered as an answer to the responsibility of scenography in contemporary cities, which, in turn, becomes a space of representation, play, or elements of the décor. The artistic environment reinvents functions of theatrical scenography, which evolves with these practices that appear to be new, so that they can reveal the dramatic potential of the city.

In Nantes, street artists instigated the first scenographic arrangements in public space. In the 1990s, artists used the urban wastelands, set their experiments under abandoned hangars and turned public space into a one-time representation space. Theatre companies took the city as a background for artistic action, and the built environment became a piece of the décor that is used to unfold fiction. The agglomeration supported these practices to create new cultural dynamics. It was about reconciling the city with a painful past, by changing the image of the industrial heritage that used to make its reputation. The Isle of Nantes - in its representation - reminded the population of the shutdown of the shipyards. The choice was to accompany these urban scenographic practices. Supported by the city, the street theatre company Royal de Luxe based itself in Nantes and found a setting for its experimentations. With the decision of funding this company, the actors of the city discover an artistic proposition that rethinks the possible relation with the city, turning it into an open scene. On the other hand, artists who are funded can come up with spectacular propositions. Thanks to a financial and logistical support, the company can imagine shows that transform the creation of the city, playing on the monumentality of the created arrangements. After its installation in the city, the first production was The True History of France. This show, presented in 1990 at the Avignon festival, represented one more step towards institutional recognition. In France, street arts are increasingly considered as an artistic field in itself, and the companies are commissioned by cities and festivals.

Royal de Luxe then developed Theatrical Accident and introduced a change of scale with its Giants. The Giants are the main characters of a show based on an urban tale for the whole city. They are monumental puppets activated by members of the company, humanising them as they move. The shows of the Giants are no longer thought as static theatre, but rather as walking spectacles with a plethora of skits over several days. 


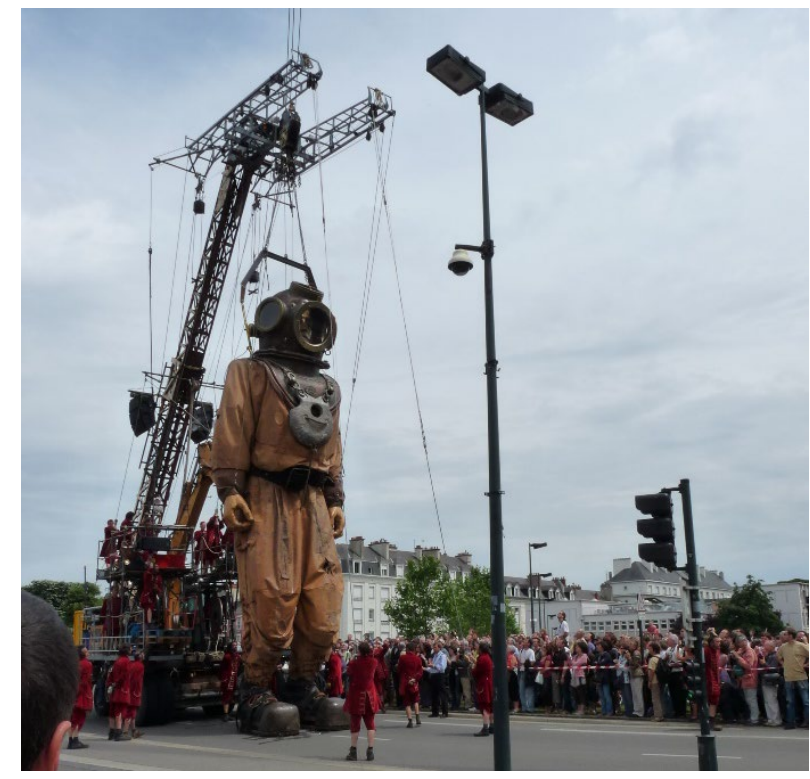

Fig. 1. The titanic giant and the diver, Nantes, Royal de luxe (2009)

At this scale and time, as Jean-Luc Courcoult states, "The viewers cannot see everything, because several events are taking place at the same time in different places" [2]. This type of show transforms the relation between creation and city. First, on dramaturgy, there is an inclusion of the viewer within the construction of the narrative. The story is given in a sequenced way, and the audience must look for the missing pieces by using its own imagination and/or by talking to the other viewers who have seen other main scenes of the show. These walking forms call in the scenographic function in the aesthetic and spatial organisation of the connections between the different scenes. The aim is to organise the representation space in relation to its context, the city and its streets to predict the relation to the public, while maintaining some mystery, so that the audience can be active. A series of scenographic effects are mobilised, such as apparition, to trigger surprise. By following the steps of the Giant who fell from the $s k y^{2}$, the audience sees the city as a décor for theatrical action. Theatre becomes an urban reality, and the city is its stage. It is no longer limited to a place, a building. Street artists build a dramatic relation with the location and question the representations and imaginations of the city. The city of Nantes, which housed the birth of the Giants, sees the possibility of using the artists' narrative that follows the characters, who, through the media and the inhabitants' memories, see Nantes in the background as an operational theatre. By addressing the relation between urban space, event and narrative, the scenographic function is democratised and relayed by the urban governance. Policies aim to maintain the dramaturgic action, in order to produce a city narrative based on the artists' stories.

\section{Perpetuation of temporary elements to build and tell the city}

With companies such as Royal de Luxe, as well as the development of art festivals like Les Allumées or Les Rendez-vous de l'Erdre, the city has gotten used to morph into a stage every once in a while. The artists have started a transformation in the practice and the view of urban space. Culture is thus considered as a tool to build a territory, according to Elsa Vivant's

${ }^{2}$ First show of the Giants. 
"global approach" [3], and the municipal structures reflect upon art in the city [4]. The metropolis thus seeks to perpetuate the imagination that the street artists convey. The story brought by the artist wove itself with the construction of a singular metropolitan identity, organised around key urban moments [5]. Driven by the success of urban parades and a temporary architecture created by the Giants, a lasting architecture was born: the Machines of the Isle of Nantes.

The Machines project represents the beginning of the second phase of cultural development policies, in which the city of Nantes aims to perpetuate artistic presences on its territory. The idea was born in 2000, after a meeting ${ }^{3}$ between François Delarozière and Pierre Orefice, when they learned that the first phase of transformation of the Isle of Nantes was launched. This proposition gradually stood out, thanks to the multiplication of temporary urban events that required artistic teams from street arts (Royal de Luxe, La Machine, Manaus) and the strong acceptance by the public. In 2003, the success of the Grand Répertoire show-exhibition, designed by La Machine in the old Alstom halls consolidated the validation of this proposition, underlying the culture of performing arts in Nantes.

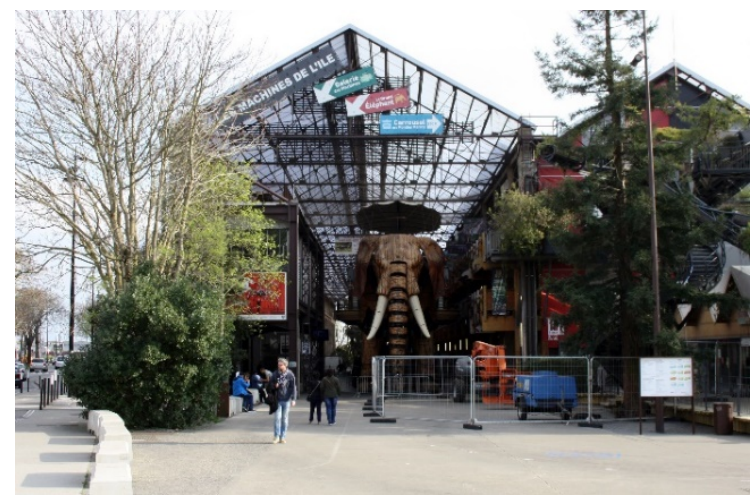

Fig. 2. The Machines of the Isle of Nantes (2019)

In 2007, the city inaugurated the Machines equipment, located under the naves of an industrial shed that was previously dedicated to port industry (Dubigeon naves). It also represents the beginning of a new phase in the urban renewal project for the Isle of Nantes, with the simultaneous launch of the Estuaire contemporary art biennale. With François Delarozière and Pierre Orefice's fantastic bestiary, the project creators, the universe of this company and the involved street artists is projected in a lasting way on the territory. The Big Elephant, key element of the project, became the emblem of a city that aims to make its cultural identity evolve. It is the symbol of a collective memory around major urban parades, while gradually distancing itself from the fictional story told by the first company during the show. Indeed, an image of the animal appeared for the first time on a poster for The Sultan of the Indies visit on his time travelling elephant show, by Royal de Luxe. The mechanical pachyderm, city machine, follows The Elephant, the machine that was designed and built by La Machine for Royal de Luxe for The Sultan of the Indies visit on his time travelling elephant show (2005). This machine perpetuated this Theatrical Accident form. The Elephant was thought for the Machines project. However, at the time, the newly created Machine company was still collaborating with Royal de Luxe as builders. François Delarozière, artistic director for La Machine company, showed his drawings of the pachyderm to Royal de Luxe's stage

\footnotetext{
${ }^{3}$ Pierre Orefice and François Delarozière met in the 1980s, while they were respectively administrator (1985-1998) and constructor-scenographer (1984-2004) for Royal de Luxe.
} 
director, who wanted to make it one of the animated automatons of the Giants. This elephant, dramaturgic element of a show, became a 1:1 prototype of the lasting version of the pachyderm.

Between the two elephants, differences in uses are noted. For Royal de Luxe, The Elephant serves fiction, whereas The Big Elephant reveals the city and is connected in a more poetic way to its past. The animal belongs to its context and echoes with the construction of an urban imagination that is turned to myths and major local figures (the construction sites filmed by Jacques Demy, references to Jules Verne or important machine inventors, like Léonard de Vinci). The visual representation of the elephant thus refers in turn to an element of a show and the architecture of a city.

With the launch of the Machines of the Isle of Nantes, a large urban tale started, layered over different levels. The myth built by the designers of the cultural equipment is disseminated by the artists themselves, as well as the communication services of the city. Based on this artistic proposition, the urban governance finds ways to largely disseminate an urban imagination that, "with the use of emblems, symbols (...) allows to appropriate a space, transfer a territorial belonging that constitutes the collective and/or individual identity" [6].

A Nantes storytelling starts with the implementation of a new narrative order that relies on the production of a cultural equipment, multiplying narratives around the universe deployed by the artists to touch on the progress of the city project. The Big Elephant is then used as an emblem - and no longer just as the symbol of an urban story from the theatre - to communicate around a creative city that "placed its bet on culture" 4 . The mechanical elephant becomes a symbol to promote local tourism with the ohlala promotional campaign ${ }^{5}$, before several structures used this figure to connote creative dynamism.

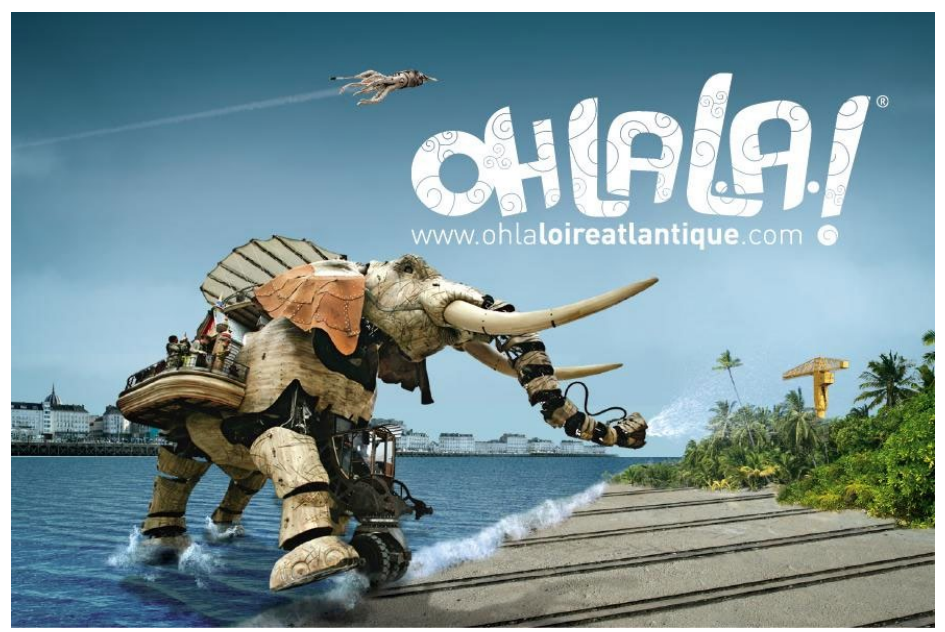

Fig. 3. Ohlala promotional campaign, Loire-Atlantique (2009)

Companies and organisations integrated the symbol in their logo to recall that they are based in Nantes. The animal was also transformed by artists, such as Jean Jullien, who caricature

\footnotetext{
${ }^{4}$ On this topic, you can read M. Grandet, Nantes la belle éveillée: le pari de la culture (2010). Several newspapers and magazines address this cultural policy, in particular the Parcours France journal, which has a special issue on the subject in October 2015.

${ }^{5}$ Ohlala is a brand created in 2009, used until 2015. A campaign with five visuals was used, two of them using the elephant as their main emblem.
} 
it, integrating it within the public space close to the equipment, participating in a spatialised narrative that physically delineates transition spaces between the Machines and the everyday urban flow. The pachyderm is turned into a logo for a city that wants to be described as creative and culturally dynamic. The inclusion of a temporary theatrical cultural also comes from this, and claims a singularity typical of Nantes.

Beyond the presence of the art piece on the territory, its image influences the construction of the urban imagination. Through the pollination of artistic motivation, the territory differentiates itself and its representations evolve. More broadly, this project impacts the identity of the metropolis through the lens of its urban ambiances. The Machines of the Isle of Nantes sets in a permanent way an immaterial heritage of images that aim at triggering emotions in the population. In an urban theatre culture, the territory is revealed in another light, and builds itself in synchronization with urban, architectural and artistic projects. They mobilise the sensory capital, deal with affects and capture the inhabitants' perceptions. Henceforth, this capital provides a new way of building the city from ambiances, and their narrative.

\section{From ambiances to the construction of a city-stage}

A scenographic culture is emerging, and it is part of the rise of a production regime of the city as a stage. The example of Nantes demonstrates that practices from the theatre join new practices in urban planning. What used to be about temporary moments is perpetuating itself, and the territory's dramatic construction influences the ways actors work with the construction of the city. Via theatre techniques applied on the city scale and by becoming a scenic city, Nantes can question indirectly the actors of the construction of city about the place of the sensory elements in urban development. The interventions done by artists, cultural operators and developers are valued in the urban construction, where each one is responsible, in his own way, of a scenographic dimension to establish a narrative, animate the territory or integrate the population. With street artists such as Royal de Luxe, it is the opportunity to scratch the surface and make urban asperities visible. With time, the artists managed to experiment with different modes of representation and to appreciate the space with a quirky attention. With a rebound effect, the population and the communication services mobilised this sensory capital, dealt with affects and captured the inhabitants' perceptions. As explained by Henri Bahrmann and Ho Van Mang, "The appreciation of space can be taught, it even improves with experience" [7]. Questions are raised around the presence of spectacular and monumental elements in the city, which compose a new aesthetical order.

The Machines project itself highlights a symbolic and physical embedding of culture in the city. Since the 1990s, the Loire metropolis has gradually opened up to all the forms of temporary and permanent scenographic equipment. As François Duconseille reminds us, "The city is understood as an artistic territory, a space to write temporary or permanent expressions, the scenography becomes urban, the world becomes a public stage to use from inside, but also to displace" [8]. The capital of the region became once again a stage for theatrical reasons, before it opened to all the arts. With the rise of festivals dedicated to contemporary art, in-situ artists have in turn integrated a scenographic dimension to socialize their pieces. Lastly, the multiplication of artistic installations available in public space calls in a scenographic dimension to create a network between the artworks and to represent the territory. Nantes integrated in its own way functions of urban scenography at the heart of it metropolitan project, between narrative, space/time management and relation to the public. When the city is superimposed to the stage, the scenography is revalued as a culture of space 
in itself, it escapes from the theatre and influences the way to imagine the construction of urban centres. The culture of temporary elements invites the production of experiences, and the integration of the population seems to be an essential component to avoid the production of a mock public space where everything would be regulated by the institution that would build the story of a factitious city with no meaning. In an agglomeration that uses culture as a lever for development, it consists in developing conditions for the interaction between a piece, its context and its public. The latter slowly exits its spot as a spectator to become an actor while the perpetuation of the scenographic culture operates.

Taking up the challenge of the inhabiting experience was made possible thanks to time management. By welcoming street performances around the Giants, the metropolis acclimated the population to the operation of prospective scenarios. Thanks to the presence of artists on the territory, the temporality is present in the shows, over a day, a week or several years. The municipal teams have gotten used to switch between seasonality and artistic production cycles. The sensory experience also operates over time and can play with it, by stopping the urban everyday time, with highlights or, on the contrary, by perpetuating fleeting moments in the implementation of a storytelling that relies on a temporary culture. The local authorities thus have grasped the abilities of artists to tell stories and establish common bases for the urban imagination, which can then be spread by the governance. Since then, these initiatives have been institutionalised, leaving physical marks in the city, with the installation of permanent pieces, elements that strike the memories, but also the trade of images, sensations and a dedicated language. This type of experience, from a culture of urban arts, infuses the room with an aesthetical dimension that is specific to it and completed by a set of temporary and urban artistic interventions.

While the convening of a long time is usual for development professionals, the institutionalization of a culture of temporary time highlights a new management for the temporalities of urban projects. On the Isle of Nantes, following the artistic teams, construction projects produce those events. They adjust depending on the uses and the room taken by the temporary artistic equipment in the story of the city. Gradually, the actors of the urban construction, through the temporary, give themselves some room to experiment and animate the present time, and prefigure uses. The perpetuation of the temporary works at different levels. The event has an influence on the time beyond its proper duration, resonating with the story of the city. The median time is used to connect what constitutes micro-events with the long time, of territorial transformations. Then, within the median time, the short time is thought to animate the present time and allow to experiment situations that could last for longer. This game of temporalities opens up possibilities to constantly experiment, adjust and sequence a territorial development project.

Moreover, the rise of the need to control the connection between artwork/viewer has a positive effect on the way we value the sensory and poetic dimension of the city. A new attention is given to the way the audience accepts the art piece and is integrated to the urban narrative. When public spaces are staged, the question of the audience's physical and symbolic implication within the story is asked. It translated in the city into the addition of signs around iconic elements, such as the Big Elephant. There is a need to experience once again the catharsis, to mitigate the tensions in urban centres and to make them pleasant to live via the production of festive urban moments. The metropolis is told like a happy city and promotes the dissemination of an image of the city where it is pleasant to live, generating nice feelings [9] and multiplying the conduct of interactive artistic experiences. Initiated by artists, the responsibility of interactivity in urban spaces on a short-term basis was relayed by the city services. However, the risk lies in turning scenography into a lever to thread the 
relationships between the inhabitants and their living spaces, where the institution would only show the right side of a spectacularisation of urban spaces. The attractivity appears to work through the production of unprecedented urban experiences that appeal to the emotions and the senses. Another risk is the gradual loss of the utopian dimension of the artistic project in a form of dependence to the city project, and the loss of autonomy for the artists in relation to the local cultural structures. It echoes with old practices, when in Roman times the theatre disappears, from scenic games - Ludi Scaenici - to circus games - gladiatorial combats with a loss of confrontation to catharsis and a return to reality.

While the figure of the city-stage appeared to be embodied by the artists, the example of Nantes shows how metropolises tend to become prescriptive of this model. Indeed, between temporary artistic interventions and delivery of an equipment coming from a street arts culture, the multiplication of experiences generates learning phenomena for the city, which has gotten used to telling itself through a game of temporalities, multiple images and in a spectacular way. Nantes grew up with the Giants, and some urban transformations are taking into account the possibility of parades. The relation to the environment is anticipated: the constraint is a pretence to establish new propositions and it becomes a stage. With the deployment of the Machines of the Isle of Nantes, the narration of the city becomes a way to make the territory attractive. We thus have a power play that is inverted, with a city organiser and producer of events, and companies that are institutionalised, to the point where they leave lasting traces of their presence on the territory. The city as a stage tells itself to its inhabitants, but also becomes a space of visibility that is prone to phenomena of patrimonalization. Therefore, the operation of the dramaturgic potential of the city by the artists encourages the consideration of the inhabitant through the ambiance and the production of unprecedented urban experiences. Between represented and place spaces, when the city becomes a stage, the user comes back to the centre of attention and can be involved in the construction of his living environment. Facing the risks of patrimonialization and of instrumentalisation of the citystage, the question is to find the ways to continue the inclusion of artists and inhabitants to make a model that perpetuate the connections between art, development and inhabitant.

\section{References}

1. E. Gangloff, Quand la scénographie devient urbaine, Nantes comme cas exploratoire des fonctions du scénographe (2017)

2. J.L. Courcoult, O.Quirot, Royal de luxe: 1993-2001, 37 (2001)

3. E. Vivant, Qu'est-ce que la ville créative? (2009)

4. C. Ruby, L'art public un art de vivre la ville (2001)

5. M. Miranda, L'événement urbain festif : vers une " gestion de site exploratoire "sur lespace public? : les cas de Nantes et de Bordeaux (2007)

6. E. Bonerandi, Géocarrefour, Le recours au patrimoine, modèle culturel pour le territoire ?, 80/2, online (2005)

7. H. Bahrmann, H. Van Mang, L'ambiance urbaine. Réflexions sur la ville et l'environnement sensible, 49 (1972)

8. F. Duconseille, J.C. Lauquetin, "Du scénographique "Porosités et extensions des pratiques et de l'enseignement de la scénographie in L. Boucris and al., "Qu'est-ce que la scénographie ?, 243 (2012)

9. L. Matthey, Building up stories. Sur l'action urbanistique à l'heure de la société du spectacle intégré, (2014) 